\title{
COMPARITIVE STUDY BETWEEN STAPLED HEMORRHOIDOPEXY AND CONVENTIONAL HEMORRHOIDECTOMY
}

Sudhir $\mathrm{M}^{1}$, J. Ramachandra², Vinayaka N. S 3

\section{HOW TO CITE THIS ARTICLE:}

Sudhir M, J. Ramachandra, Vinayaka N. S. "Comparative Study between Stapled Hemorrhoidopexy and Conventional Hemorrhoidectomy". Journal of Evolution of Medical and Dental Sciences 2014; Vol. 3, Issue 10, March 10; Page: 2519-2527, DOI: 10.14260/jemds/2014/2166

\begin{abstract}
AIM: The aim of the study was to compare the results of stapled haemorroidopexy and open haemorrhoidectomy. METHODS: The study population consisted of 60 patients who were admitted with hemorrhoids to a Medical college hospital providing primary, secondary and tertiary care. Patients were allocated to both groups on random basis. The main outcome measures were, time taken for each surgical procedure, the intra- operative bleeding, Post- operative pain (visual analog scale), time taken for first defecation after operation, Duration of hospital stay and Time taken to return to work. Follow up was conducted for minimum period of 6 months. RESULTS: Stapled v/s conventional haemorrhoidectomy was associated with significantly reduced operating time $(30.13 \pm 5.97 \mathrm{v} / \mathrm{s} 47.67 \pm 8.28$ minutes; $\mathrm{p}=0.001)$, Less blood loss during stapled $\mathrm{v} / \mathrm{s}$ open haemorrhoidectomy (12.33 ml and $21.83 \mathrm{ml} ; \mathrm{p}=0.001$ ), Reduced post-operative pain scores (Visual Anolog Score) on the first 4 post-operative days (day 1: $4.63 \mathrm{v} / \mathrm{s} 5.70$, day 2: $2.70 \mathrm{v} / \mathrm{s}$ 4.57, day 3: 1.83 $\mathrm{v} / \mathrm{s} 3.70$ and day $4: 1.2 \mathrm{v} / \mathrm{s} 3.10$, where 0 indicates no pain and 10, maximum pain; $\mathrm{p} \leq 0.001$ ), Patients who underwent stapled haemorrhoidectomy passed stools earlier $(22.10 \pm 3.75 \mathrm{hrs}$. and $26.03 \pm 3.77$ hrs: $\mathrm{p} \leq 0.001$ ) than conventional group. Reduced number of hospital stay in stapled group $(3.83 \pm 0.87 \mathrm{v} / \mathrm{s} 6.70 \pm 1.82$ days: $\mathrm{p} \leq 0.001)$ compared to conventional group. Anal stricture noted in two patients in stapled group compared to 4 patients in open group. CONCLUSIONS: Stapled haemorroidopexy is associated with reduced operating time, less blood loss during surgery, reduced post-operative pain, less number of hospital admission days, early return to work. It is a safe and effective procedure for haemorrhoids; it may become a gold standard procedure for haemorrhoids in future.
\end{abstract}

KEYWORDS: Stapled haemorroidopexy, Conventional haemorrhoidectomy.

INTRODUCTION: Haemorrhoids are one of the most common anorectal disorders. The term HEMORRHOIDS is derived from the Greek adjective meaning bleeding (haima=bleed, rhoos=flowing) and emphasizes the most important symptom of this disease ${ }^{1}$. The word PILE derived from Latin word "pila" meaning ball, can be applied to all patients presenting with this disease as every patient with this disease present with some sort of swelling 2. John Goligher says "at least $50 \%$ of the people over the age of fifty have some degree of haemorrhoid formation." 3 Conventional haemorrhoidectomy $(\mathrm{CH})$ is the most commonly practiced surgical procedure and is considered the gold standard in the treatment of piles, but conventional excision is a notoriously painful operation. Most patients have pain on defecation and discomfort at rest in the second and third weeks after surgery because of wound infection and sphincter spasm. Stapled haemorrhoidopexy, often also called stapled haemorrhoidectomy, was introduced in 1998 as an alternative to the closed Ferguson and open Milligan-Morgan techniques for the operative management of haemorrhoidal disease by 


\section{ORIGINAL ARTICLE}

Longo ${ }^{4}$ and is characterized by the transanal introduction of a circular staple to excise redundant rectal mucosa.

The theoretical benefits of stapled haemorrhoidopexy are three-fold. First, the interruption of inflow from the superior haemorrhoidal arteries to the internal haemorrhoids may contribute to improvement of haemorrhoidal symptoms by relieving vascular congestion. Secondly, the partial excision of the haemorrhoidal cushions themselves reduces the size of the internal haemorrhoids. Thirdly, resection of rectal mucosa reduces the tendency to prolapse and restores the internal cushions to their normal physiological position. ${ }^{5}$

Several studies comparing stapled haemorrhoidopexy with traditional excisional haemorrhoidectomy have shown it to be less painful and that it is associated with quicker recovery.5,6 The reports also suggest a better patient acceptance and a higher compliance with day-case procedures potentially making it more economical. ${ }^{7}$

MATERIALS AND METHODS: The study was conducted between June 2009 and September 2011 at Kempegowda Institute of Medical Sciences Hospital, Bangalore, Karnataka, India. This study included a total number of 60 patients with a minimum follow-up of 6 months. Of the total of 60 patients in the study, 30 patients underwent stapled haemorroidopexy, 30 patients underwent conventional haemorrhoidectomy procedure. Patients were allocated to both groups on random basis.

INCLUSION CRITERIA: All patients who presented with symptomatic haemorrhoids in all age groups and both sexes were included in this study.

EXCLUSION CRITERIA: patients with acute episodes of thrombosed haemorrhoids, coexisting anal diseases, inflammatory bowel diseases, tuberculosis and patients with secondary haemorrhoids due to an intra-abdominal pathology were excluded from the study.

All the patients received prophylactic antibiotics in the preoperative period and also an enema, either soap water or proctoclysis.

OPERATIVE TECHNIQUE: All the procedures were performed under spinal anesthesia (Sub Arachnoid Block), and the patient was placed in the lithotomy position for all the procedures.

Open haemorrhoidectomy: Proctoscopy done initially under anesthesia to assess the degree, position of haemorrhoids and to rule out other pathologies. Digital dilatation of the anus is done. With traction on the haemorrhoids $\mathrm{V}$ shaped incision is made in the anal and the perianal skin, haemorrhoids is dissected and its pedicle transfixed and ligated. After securing the ligature and clearing other haemorrhoids in a similar fashion, the pile mass is excised leaving behind a raw surface.

Stapled haemorroidopexy: After initial Proctoscopy, circular anal dilator (CAD 33) introduced, obturator removed and the dilator fixed to perineum by stitches. Purse string suture (PSA 33) anoscope is introduced through the CAD 33. Then $5 \mathrm{~cm}$ proximal to the dentate line purse string stitches of the entire circumference of the anal mucosa taken. PSA 33 is removed. The head of the haemorrhoidal circular stapler (HCS 33) after opening to its maximal position is introduced and positioned proximal to the purse string, which is then tied. The entire casing of the HCS 33 is then introduced into the anal canal and tightened with partial traction on the purse string suture. After completion of the tightening the device is left in its position for 20 seconds to allow tamponade and 
improve hemostasis. The gun is fired after releasing the safety catch, after waiting for another 20 seconds the HCS 33 is completely opened and removed together with the CAD 33 from the anal canal. The suture line is inspected for any gaps using PSA 33, and the specimen for its doughnut appearance.

ASSESSMENT: The duration of the surgery is noted. Post-operative pain was assessed using visual analog scale (VAS) in which 0 corresponds to no pain and 10 , maximum pain. All patients were administered either inj. Tramadol $50 \mathrm{mg}$ or Inj. Diclofenac Sodium $75 \mathrm{mg}$ (intramuscularly) in immediate post op period.

Post-operative parameters like the time taken for first defecation after operation and pain and bleeding associated with it were assessed.

Early post-operative complications like urinary retention, secondary bleeding, anal incontinence, wound infection were compared.

Patients' length of hospital stay and time taken to return to work were compared.

FOLLOW UP: Examination was conducted for minimum period of 6 months. Late post-operative complications like anal stenosis, recurrence and other complaints were compared between the two procedures.

\section{RESULTS:}

AGE DISTRIBUTION: The youngest patient was $20 \mathrm{yrs}$. and the oldest was $75 \mathrm{yrs}$. old in our study. (Table: 1 and chart 1).

SEX DISTRIBUTION: The majority of the patients included in the study were males. 24 patients each in stapled and conventional group. (Table: 2 ).

DEGREE OF HEMORRHOIDS: In our study, 28 patients had grade II and 32 patients had grade III haemorrhoids.

OPERATING TIME: The average time taken for a stapled haemorrhoidopexy was $30.13 \pm 5.97$ mins, and 47.67 \pm 8.28 mins for Conventional haemorrhoidectomy. (Table: 3 ).

BLOOD LOSS DURING SURGERY: The blood loss during surgery was calculated based on the number of $4 \times 4$ gauzes that was fully soaked, each gauze piece being qualified as $10 \mathrm{ml}$. the average blood loss during stapled and open haemorrhoidectomy was $12.33 \mathrm{ml}$ and $21.83 \mathrm{ml}$ respectively. (Table: 3 ).

POST - OPERATIVE PAIN (Visual Analog Score): The average pain scores on post op day 1, day 2, day 3and day 4 in the stapled group was 4.63, 2.70, 1.83 and 1.2 as against 5.70, 4.57, 3.70 and 3.10 in the conventional group. (Table: 5).

TIME TAKEN FOR FIRST DEFECATION AFTER SURGERY: The average time for passage of first stools in the stapled and open group was $22.10 \pm 3.75 \mathrm{hrs}$. and $26.03 \pm 3.77 \mathrm{hrs}$. respectively. (Table: 3 ). 12 patients in the stapled group complained of mild bleeding, compared to 15 cases of mild and 7 cases of moderate bleeding in conventional group.

Post-operative complications: 2 patients in the stapled and 11 patients in the conventional group developed urinary retention requiring in dwelling catheters. 1 patient in stapled and 4 patients in conventional haemorrhoidectomy group developed post op nausea and vomiting on post op day 1 .

1 patient in stapled and 7 patients in conventional group developed headache following surgery which was treated as an anesthetic complication and patients were hydrated and advised bed rest. 
DURATION OF HOSPITAL STAY: The average duration of stay in the hospital for the stapled group was $3.83 \pm 0.87$ days and $6.70 \pm 1.82$ days for the conventional group. (Table: 3 )

TIME TAKEN TO RETURN TO WORK: The time duration in the stapled group was $5.43 \pm 1.33$ days as against $10.57 \pm 3.46$ days in the conventional group. (Table: 3 )

LATE POST-OPERATIVE COMPLICATIONS: Anal stricture noted in two patients in stapled group compared to 4 patients in conventional group. One patient in the conventional group developed recurrence.

Statistical analysis: The data in this study is analyzed using SPSS version 21. The descriptive statistics like mean, SD, 95\% confidence interval for mean as well as mean differences are computed. VAS score for pain is analyzed using repeated measures for ANOVA and Greenhouse-Geisser F-value is considered here because the assumption on sphericity has failed.

DISCUSSION: Among the newer surgical options currently available, haemorrhoidectomy performed by the Longo-Milton technique using circular anal stapler is said to result in less postoperative pain and complications, and early return to work ${ }^{5,6}$.

The operating time as found to be much less in the stapled group $(30.13 \pm 5.97 \mathrm{v} / \mathrm{s} 47.67 \pm 8.28$ mins; $p=0.001$ ) (Table: 4) compared to the conventional group. This is comparable with other studies like Franc H. Hetzer et al ${ }^{8}$, Jinn Shiun Chin et al ${ }^{9}$, Jai Bickchandani et al ${ }^{10}$, but a study done by Eric Touzin 11 did not show much difference in operating time.

Intraoperative blood loss was lesser in the stapled group $(12.33 \mathrm{v} / \mathrm{s} 21.83 \mathrm{ml}$ average; $\mathrm{p}=$ 0.001) (Table:4) as compared to conventional group, this has been well documented in other studies like Eric Touzin et al ${ }^{11}$, Marc Singer et al ${ }^{12}$.

Post-operative pain scores by VAS were significantly favorable in stapled group at $24 \mathrm{hrs,}$ 48hrs, 72hrs, and 96 hrs. (Table: 5) Which can be explained as it does involve any surgery in the sensitive anal mucosa below the dentate line. Stapled haemorroidopexy obtains circumferential resection of rectal mucosa in the anal canal, thus preserving the integrity of haemorrhoidal cushions and simultaneously restoring the anal mucosa, the haemorrhoidal cushions and anoderma upwards in the anal canal to their original position thus, restoring normal physiology resulting in less complications. Mean pain scores in several studies like Franc H. Hetzer et al. ${ }^{8}$ Jean Francois et al 13, Antonio Lacerda-Filho et al, ${ }^{14}$ Ali Athar et al, ${ }^{15}$ Carlos Walter Sobrado et al ${ }^{16}$ and Sergio Carlos Nahas et al 17 has shown that post-operative pain is less after stapled technique.

The time for passage of first stools post-surgery was less in the stapled group $(22.10 \pm 3.75$ hrs. and $26.03 \pm 3.77$ hrs: $p \leq 0.001$ ), (Table: 4 ) in comparison to the other group; similar to the results obtained in other studies.

The rate of complications seen in the conventional group were more compared to stapled group, most common complications were urinary retention(2 in the stapled group and 11 in the open group). Eric Touzin et $\mathrm{al}^{11}$ found similar complications in the early post-operative period. Another study by Ali Athar et al ${ }^{15}$ showed that early post-operative complications are much less in stapled group. Carlos Walter Sobrado et al, ${ }^{16}$ Shalaby et al ${ }^{18}$ and Mehigan BJ et al, ${ }^{19}$ also showed similar results. Richard G Molloy and Kingsmore ${ }^{20}$ reported a case of severe retroperitoneal sepsis following stapled procedure and they suggest routine use of prophylactic antibiotics before the procedure. In our series all patients received prophylactic antibiotics and no patients developed sepsis. There are two case reports of rectal perforation and one case report of a rectovaginal fistula after stapled 
procedure, and acute intestinal obstruction due to closure of the rectum by purse string sutures. These complications are suggested to have happened due to inadequate experience and can be overcome once learning curve is passed.

The duration of hospital stay was significantly lesser in the stapled group; one of the reasons for prolonged stay in the conventional group was the post-operative pain. Eric Touzin et al ${ }^{11}$, Racalbuto et al,21 Marc singer et al,12 Shalaby et al18 and Law WL et al22 found similar results in their study.

The time of return to normal work was much lesser in the stapled group $(5.43 \pm 1.33 \mathrm{v} / \mathrm{s}$ 10.57 $\pm 3.46 ; \mathrm{p} \leq 0.001$ ) (Table: 4 ) when compared to the conventional group. Racalbuto A et $\mathrm{al}^{21}$ showed similar reports.

At the end of the study period the follow up was $77 \%$ in the open group and $73 \%$ in the stapled group. The average duration of follow up was 17 months with the longest follow up of 26 months in the stapled group and the average follow up of 12 months with the longest follow up of 23 months in the conventional group. In the stapled group two patients had anal stricture at the end of the study. In case of conventional haemorrhoidectomy group four patients had anal stricture and one patient had recurrence at the end of the study. Racalbuto et al ${ }^{21}$ showed the rate of anal stricture is higher in conventional group. Jinn Shiun et al ${ }^{9}$ found no difference in anal stenosis amongst both the procedures.

CONCLUSION: Conventional haemorrhoidectomy, performed either with the open or closed technique, is an effective cure for haemorrhoids and has minimal complications, but has increased postoperative pain, prolonged hospital stay and longer duration to return to work when compared to stapled haemorrhoidectomy. Stapled haemorrhoidectomy is safe with many short term benefits like less post-operative pain, early return from hospital and early return to their normal activity.

Stapled haemorroidopexy is a safe procedure for second-degree and third-degree haemorrhoids. It might become the gold standard in the management of haemorrhoids in future.

\section{REFERENCES:}

1. Peterlunniss and Karen Nugent. The anus and anal canal. In. Norman S. Williams, Christopher J.K. Bulstrode, P. Ronan O'Connell(ed) BAILEY \& LOVE'S Short practice of Surgery, 26th edn. CRC Press, 1236-1269.

2. Goligher J C. Surg anus, rectum, colon.5th edition. Bailliare Tindall - London. 1984: 98-149.

3. Ferguson JA, Heaton JR. Closed haemorrhoidectomy. Dis colon, rectum 1959; 2: 176.

4. Longo A. Treatment of haemorrhoids disease by reduction of mucosa and haemorrhoidal prolapse with circular suturing device: a new procedure. 6th World Congress of Endoscopic Surgery; Rome; 1998:777-784.

5. U Sabanci, I Ogun, G Candemir. Stapled Haemorrhoidopexy versus Ferguson Haemorrhoidectomy: a Prospective Study with 2-Year Postoperative Follow-up. The Journal of International Medical Research 2007; 35: 917 - 921.

6. ASMT Rahma, ASMZ Rahman, SK Biswas, KR Majumder, G Biswas. Stapled Haemorrhoidopexy Compared with Conventional Haemorrhoidectomy--A Systematic Review. Faridpur Med. Coll. J. 2012; 7(1): 37-41. 
7. R. Kushwaha, W. Hutchings, C. Davies and N. G. Rao. Randomized clinical trial comparing daycare open haemorrhoidectomy under local versus general anaesthesia. British Journal of Surgery 2008; 95: 555-563.

8. Franc H. HETZER, Nicolas Dermartines, Alexander E. Handschin, Pierre-Alain Clavien. Stapled vs. Excision haemorrhoidectomy. Long term results of a prospective randomized trial. Arch Surg. 2002; 137(3):337-340. doi:10.1001/archsurg.137.3.337.

9. Jinn-Shiun Chen, Jeng-Fu You. Current Status of Surgical Treatment for Haemorrhoids Systematic Review and Meta-analysis. Chang Gung Med J Vol. 33 No. 5 September-October 2010.

10. Jai Bickchandani, Agarwal PN, Ravikant, Malik VK. Randomized controlled trial to compare the early and midterm results of stapled vs. open haemorrhoidectomy. Am J Surg 2005; 189: 56-60.

11. Eric Touzin, Susan Hegge, and Craig McKinley. Early experience of stapled haemorrhoidectomy in a community hospital setting. Can J Surg, Vol. 49, No. 5, October 2006. 316-320

12. Marc Singer and Herand Abcarian. Stapled Haemorrhoidopexy: The Argument for Usage. Clinics in colon and rectal surgery/volume 17, number 2 2004. 130-142.

13. Jean François Gravié, MD, Paul-Antoine Lehur, MD, Noël Huten, MD, Marc Papillon, Michel Fantoli, Bernard Descottes, Patrick Pessaux, and Jean-Pierre Arnaud. Stapled Hemorrhoidopexy Versus Milligan-Morgan Hemorrhoidectomy. A Prospective, Randomized, Multicenter Trial with 2-Year Postoperative Follow Up. Ann Surg. 2005 July; 242(1): 29-35. doi:10.1097/01.sla.0000169570.64579.31.

14. Antonio Lacerda-Filho; Rodrigo Gomes da Silva. Stapled hemorrhoidectomy: present status. Arq.Gastroenterol.vol.42 no.3 São Paulo July/Sept. 2005. doi.org/10.1590/S000428032005000300013.

15. Ali Athar, Tabish Chawla, and Pishori Turab. Stapled Hemorrhoidopexy: The Aga Khan University Hospital Experience. Saudi J Gastroenterol. 2009 July; 15(3): 163-166. doi: 10.4103/1319-3767.45358.

16. Carlos Walter Sobrado; Guilherme Cutait de Castro Cotti; Fabricio Ferreira Coelho; Júlio Rafael Mariano da Rocha. Initial experience with stapled hemorrhoidopexy for treatment of haemorrhoids.Arq.Gastroenterol.vol.43 no.3 São Paulo July/Sept. 2006. doi.org/10.1590/S0004-28032006000300016.

17. Sergio Carlos Naha, Marcelo Rodrigues Borba, Maria Cecília Teixeira Brochado, Carlos Frederico Sparapan Marques, CaioSérgio RizkallahNahas, Boulanger Miotto-Neto. Stapled hemorrhoidectomy for the treatment of haemorrhoids. Arq. Gastroenterol. vol.40 no.1 São Paulo Jan./Mar. 2003. doi.org/10.1590/S0004-28032003000100008.

18. Shalaby R, Desoky A. Randomized clinical trial of stapled versus Milligan-Morgan haemorrhoidectomy. Br J Surg. 2001 Aug;88(8):1049-53.

19. Mehigan BJ, Monson JR, Hartley JE. Stapling procedure for haemorrhoids versus MilliganMorgan haemorrhoidectomy: randomised controlled trial. The Lancet Volume 355, Issue 9206, 4 March 2000, Pages 782-785.

20. Richard G Molloy and Kingsmore. Life threatening pelvic sepsis after stapled haemorrhoidectomy. The Lancet, Vol 355, Issue 9206, Pg 810, 4 March 2000.doi:10.1016/S01406736(00)02208X. 


\section{ORIGINAL ARTICLE}

21. A. Racalbuto, I. Aliotta, M. Santangelo, R. Lanteri, P.V. Foti1, V. Minutolo, A. Licata. Hemoperitoneum as severe and unusual complication in the stapler recto-anopexy for hemorrhoidal prolapse: Case report. G Chir 32: May 2011 ; 272-274..

22. Law WL, Tung HM, Chu KW, Lee FC. Ambulatory stapled haemorrhoidectomy: a safe and feasible surgical technique. Hong Kong Med J. 2003 Apr;9(2):103-7.

\begin{tabular}{|c|c|c|c|}
\hline \multirow{2}{*}{ Age (yrs) } & \multicolumn{2}{|c|}{ Type of Surgery } & \multirow{2}{*}{ Total } \\
\cline { 2 - 3 } & Stapled & Conventional & \\
\hline$\leq 20$ & 1 & 1 & 2 \\
\hline $21-30$ & 4 & 5 & 9 \\
\hline $31-40$ & 6 & 7 & 13 \\
\hline $41-50$ & 10 & 10 & 20 \\
\hline $51-60$ & 5 & 3 & 8 \\
\hline $61-70$ & 4 & 2 & 6 \\
\hline $71-80$ & & 2 & 2 \\
\hline Total & 30 & 30 & 60 \\
\hline
\end{tabular}

Table 1

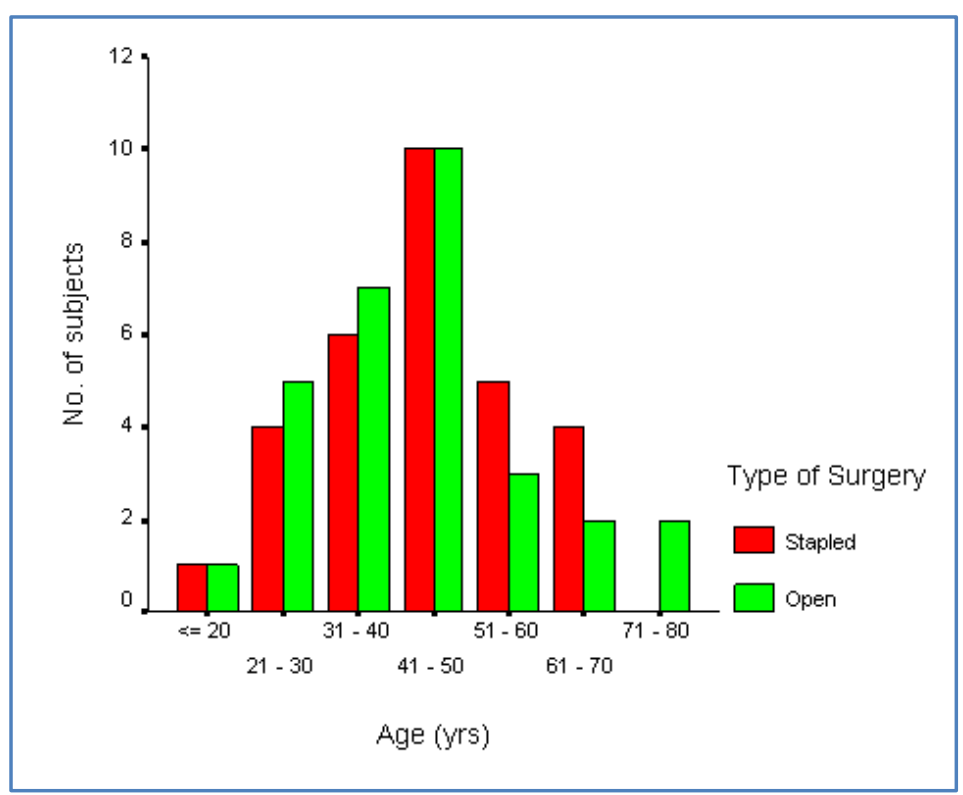

\begin{tabular}{|c|c|c|c|}
\hline \multirow{2}{*}{ Sex } & \multicolumn{2}{|c|}{ Type of Surgery } & \multirow{2}{*}{ Total } \\
\cline { 2 - 3 } & Stapled & conventional & \\
\hline Male & 24 & 24 & 48 \\
\hline Female & 6 & 6 & 12 \\
\hline Total & 30 & 30 & 60 \\
\hline \multicolumn{4}{|c|}{ Table 2 } \\
\hline
\end{tabular}


ORIGINAL ARTICLE

\begin{tabular}{|c|c|c|c|c|c|c|}
\hline \multirow{2}{*}{ Parameters } & \multicolumn{3}{|c|}{ Stapled } & \multicolumn{3}{c|}{ Conventional } \\
\cline { 2 - 7 } & Mean & $\begin{array}{c}\text { Std. Error } \\
\text { Mean }\end{array}$ & $\mathbf{9 5 \%}$ CI & Mean & $\begin{array}{c}\text { Std. Error } \\
\text { Mean }\end{array}$ & $\mathbf{9 5 \% ~ C I ~}$ \\
\hline $\begin{array}{c}\text { Intraoperative } \\
\text { time (min) }\end{array}$ & $30.13 \pm 5.97$ & 1.09 & $(27.90,32.36)$ & $47.67 \pm 8.28$ & 1.51 & $(44.58,50.76)$ \\
\hline $\begin{array}{c}\text { Blood loss } \\
\text { (ml) }\end{array}$ & $12.33 \pm 5.53$ & 1.01 & $(10.27,14.40)$ & $21.83 \pm 8.36$ & 1.53 & $(18.71,24.95)$ \\
\hline $\begin{array}{c}\text { First stools time } \\
\text { (hrs) }\end{array}$ & $22.10 \pm 3.75$ & 0.68 & $(20.70,23.50)$ & $26.03 \pm 3.77$ & 0.69 & $(24.62,27.44)$ \\
\hline $\begin{array}{c}\text { Hospital stay } \\
\text { (days) }\end{array}$ & $3.83 \pm 0.87$ & 0.16 & $(3.51,4.16)$ & $6.70 \pm 1.82$ & 0.33 & $(6.02,7.38)$ \\
\hline $\begin{array}{c}\text { Time to return } \\
\text { to work }\end{array}$ & $5.43 \pm 1.33$ & 0.24 & $(4.94,5.93)$ & $10.57 \pm 3.46$ & 0.63 & $(9.27,11.86)$ \\
\hline
\end{tabular}

\begin{tabular}{|c|c|c|c|c|c|}
\hline Parameters & $\begin{array}{c}\text { Mean } \\
\text { Difference }\end{array}$ & $\begin{array}{c}\text { Std. Error } \\
\text { Difference }\end{array}$ & $\begin{array}{c}\text { 95\% Confidence } \\
\text { Interval of the } \\
\text { Difference }\end{array}$ & t-value & P-value \\
\hline $\begin{array}{c}\text { Intraoperative } \\
\text { time (min) }\end{array}$ & -17.53 & 1.86 & $(-21.26,-13.80)$ & 9.407 & 0.001 \\
\hline Blood loss (ml) & -9.50 & 1.83 & $(-13.16,-5.84)$ & 5.194 & 0.001 \\
\hline $\begin{array}{c}\text { First stools time } \\
\text { (hrs) }\end{array}$ & -3.93 & 0.97 & $(-5.88,-1.99)$ & 4.052 & 0.001 \\
\hline $\begin{array}{c}\text { Hospital stay } \\
\text { (days) }\end{array}$ & -2.87 & 0.37 & $(-3.61,-2.13)$ & 7.769 & 0.001 \\
\hline $\begin{array}{c}\text { Time to return to } \\
\text { work }\end{array}$ & -5.13 & 0.68 & $(-6.49,-3.78)$ & 7.583 & 0.001 \\
\hline
\end{tabular}

Table 4

\begin{tabular}{|c|c|c|c|c|}
\hline $\begin{array}{l}\text { VAS score of } \\
\text { stapled group }\end{array}$ & Mean & Std. Deviation & $\begin{array}{c}\text { Greenhouse-Geisser } \\
\text { F - value }\end{array}$ & P-value \\
\hline POD 1 & 4.63 & 1.38 & \multirow{4}{*}{120.062} & \multirow{4}{*}{0.001} \\
\hline POD 2 & 2.70 & 0.92 & & \\
\hline POD 3 & 1.83 & 0.75 & & \\
\hline POD 4 & 1.20 & 0.41 & & \\
\hline $\begin{array}{c}\text { VAS score of } \\
\text { conventional group }\end{array}$ & Mean & Std. Deviation & $\begin{array}{c}\text { Greenhouse-Geisser } \\
\text { F - value }\end{array}$ & P-value \\
\hline POD 1 & 5.70 & 0.65 & \multirow{4}{*}{112.094} & \multirow{4}{*}{0.001} \\
\hline POD 2 & 4.57 & 0.90 & & \\
\hline POD 3 & 3.70 & 0.70 & & \\
\hline POD 4 & 3.10 & 0.88 & & \\
\hline
\end{tabular}


ORIGINAL ARTICLE

\begin{tabular}{|l|c|c|c|c|c|}
\hline & Type of Surgery & $\mathrm{N}$ & Mean & Std. Deviation & Std. Error Mean \\
\hline POD 1 & Stapled & 30 & 4.63 & 1.377 & .251 \\
\hline & Open & 30 & 5.70 & .651 & .119 \\
\hline POD 2 & Stapled & 30 & 2.70 & .915 & .167 \\
\hline & Open & 30 & 4.57 & .898 & .164 \\
\hline POD 3 & Stapled & 30 & 1.83 & .747 & .136 \\
\hline & Open & 30 & 3.70 & .702 & .128 \\
\hline POD 4 & Stapled & 30 & 1.20 & .407 & .074 \\
\hline & Open & 30 & 3.10 & .885 & .162 \\
\hline \hline
\end{tabular}

\begin{tabular}{|c|c|c|c|c|c|c|c|}
\hline & $\begin{array}{c}\text { t-test for Equality } \\
\text { of Means }\end{array}$ & $\mathrm{df}$ & $\begin{array}{c}\text { Sig. } \\
\text { (2-tailed) }\end{array}$ & $\begin{array}{c}\text { Mean } \\
\text { Difference }\end{array}$ & $\begin{array}{c}\text { Std. Error } \\
\text { Difference }\end{array}$ & $\begin{array}{c}\text { 95\% Confidence } \\
\text { Interval of the } \\
\text { Difference }\end{array}$ & \\
\hline & & & & & & Lower & Upper \\
\hline POD 1 & -3.836 & 58 & .000 & -1.07 & .278 & -1.623 & -.510 \\
\hline POD 2 & -7.975 & 58 & .000 & -1.87 & .234 & -2.335 & -1.398 \\
\hline POD 3 & -9.975 & 58 & .000 & -1.87 & .187 & -2.241 & -1.492 \\
\hline POD 4 & -10.687 & 58 & .000 & -1.90 & .178 & -2.256 & -1.544 \\
\hline & & & & & & \\
\hline
\end{tabular}

\section{AUTHORS:}

1. Sudhir M

2. J. Ramachandra

3. Vinayaka N.S.

\section{PARTICULARS OF CONTRIBUTORS:}

1. Associate Professor, Department of General Surgery, KIMS Hospital, Bangalore.

2. Professor, Department of General Surgery, KIMS Hospital, Bangalore.

3. PG Student, Department of General Surgery, KIMS Hospital, Bangalore.

\section{NAME ADDRESS EMAIL ID OF THE} CORRESPONDING AUTHOR:

Dr. Sudhir M,

Associate Professor,

Department of General Surgery,

KIMS Hospital, K.R. Road,

V.V. Puram, Bangalore - 4.

E-mail: drsudhirm@gmail.com

Date of Submission: 11/02/2014.

Date of Peer Review: 12/02/2014.

Date of Acceptance: 20/02/2014.

Date of Publishing: 05/03/2014. 